\title{
Oral Bisphosphonates and Relationship to ONJ and Dental Implants
}

\section{Pouran Famili*}

Department of Periodontics and Preventive Dentistry, University of Pittsburgh School of Dental Medicine, Pittsburgh, Pennsylvania, USA

\begin{abstract}
Osteoporosis is a multifactorial, systemic skeletal disease generally affecting older females. It reduces bone mineral density and decreases bone strength, resulting in increased bone fragility and risk of bone fracture(s). Dental implants meanwhile are increasingly sought out by this population. It is clinically necessary to understand the effect of implant success on patients with skeletal low bone mineral density who is also receiving treatment for osteoporosis with oral bisphosphonates. In our ongoing research regarding once-yearly IV bisphosphonate zoledronic acid to prevent osteoporosis in elderly nursing home patients, to date 252 patients have been followed one year after treatment. No osteonecrosis of the jaw has been observed. Collaborative ongoing research by this author has shown dental implants can survive regardless of osteoporosis and even taking bisphosphonates for treatment of osteoporosis. Follow-up for two years on twenty patients has shown no failing implants.
\end{abstract}

Keywords: Osteoporosis; Bisphosphonate; Dental implant; Osteonecrosis of the Jaw (ONJ)

\section{Review}

Bisphosphonates were introduced in the mid-1990s as an alternative to hormone replacement therapies for treatment of osteoporosis. In 1996 Fosamax $^{\oplus}$ (alendronate, marketed by Merck) was the first bisphosphonate drug approved in the U.S. for the treatment of osteoporosis. The pharmaco-function of bisphosphonates remains relatively unclear. Bisphosphonates bind and accumulate in bone and remain there for months after therapy is discontinued.

Bisphosphonates may also contribute to an inhibition of bone resorption and an increase in bone mass. Although the bisphosphonate drugs block bone resorption, bone formation continues for about six to twelve months, after which formation then stops. Thus the newlymineralized bone is more densely packed so that individual bone density will increase even though the bone volume does not.

Wang et al. [1] reported the first case of osteonecrosis of the jaw $(\mathrm{ONJ})$ associated with bisphosphonate therapy in cancer patients. These cancer patients were undergoing many treatments with chemotherapy drugs, corticosteroids, and then also bisphosphonates. The majority of reported cases of bisphosphonates associated with ONJ have been diagnosed after invasive dental procedures such as tooth extraction. Less commonly ONJ appears to occur spontaneously in patients taking the bisphosphonates [2]. Initial reports showed that ONJ was mainly associated with metastatic breast cancer and multiple myeloma [3] and it was clear that patients taking higher cumulative doses of bisphosphonates had greater risk of developing ONJ. ONJ is more prevalent in patients with malignancies than patients with benign bone disorders [4].

Further, Hoff et al. suggested that the fact should not be overlooked that bisphosphonates offer major therapeutic benefits to individuals with metastatic and metabolic bone disease [4]. Bisphosphonate therapy should remain an important medical treatment yet there are a number of implications for dentistry. Dental therapy for the increasing numbers of aging women being prescribed bisphosphonates in treatment for post-menopausal osteoporosis should focus on prevention of ONJ by management of dental disease.

Osteoporosis is a common bone-resorptive, host-dependent, multifactorial and systemic skeletal disease generally affecting older females, marked by reduced bone strength, and decreased bone mineral density and microarchitectural deterioration of bone tissue, resulting in increased bone fragility and risk of bone fracture [5]. Dental implants meanwhile are increasingly sought out by the same aging population. It is clinically necessary to understand the effect on dental implant success of skeletal low bone mineral density and treatment for osteoporosis with oral bisphosphonates. Most investigations conclude that no compelling theoretical or practical basis exists to expect osteoporosis to be a risk factor for osseointegrated dental implants [6-9].

It is estimated that more than five million people are annually treated with oral bisphosphonates for osteoporosis [10]. Patients taking the oral bisphosphonates have a lower incidence of ONJ [11]. In at-risk populations alendronate and risedrontate $\left(\right.$ Actonel $^{\circ}$, Warner Chilcott Laboratories) are potent second-generation oral bisphosphonates which can reduce the risk of hip and vertebral fracture by as much as fifty percent [12]

In our ongoing research we hypothesized that once-yearly IV bisphosphonate zoledronic acid (Zometa ${ }^{\star}$ or Reclast $^{\circledR}$ by Novartis) to prevent osteoporosis in elderly nursing home patients may cause ONJ. So far 252 patients have been screened and followed one year after conclusion of IV bisphosphonate treatment. No osteonecrosis of the jaw has been observed in any case.

Collaborative ongoing research by this author investigating dental implants placed in post-menopausal women has shown that women have the same dental implant survival potential regardless of bisphosphonate use. Follow-up for two years on twenty patients has shown no failing dental implants or ONJ (unpublished data, this author). Likewise oral bisphosphonates did not have the reverse effect on dental implants and we did not observe any osteonecrosis of the jaw. These conclusions, while promising for the clinician placing dental implants, demand further investigations with significantly larger populations over longer periods of bisphosphonate treatment exposure.

*Corresponding author: Chair and Director of the Residency Program, Department of Periodontics and Preventive Dentistry, University of Pittsburgh School of Dental Medicine, Pittsburgh, Pennsylvania, B94 Salk Hall 3501 Terrace Street Pittsburgh PA 15261, USA, Tel: 412-648-8598; E-mail: pof@pitt.edu

Received December 20, 2013; Accepted December 25, 2013; Published December 27, 2013

Citation: Famili P (2013) Oral Bisphosphonates and Relationship to ONJ and Dental Implants. Dentistry 4: 188. doi:10.4172/2161-1122.1000188

Copyright: (C) 2013 Famili $P$. This is an open-access article distributed under the terms of the Creative Commons Attribution License, which permits unrestricted use, distribution, and reproduction in any medium, provided the original author and source are credited. 


\section{References}

1. Wang EP, Kaban LB, Streler GJ, Raje N, Troulis MJ (2003) Incidence of osteonecrosis of the jaw in patients with multiple myeloma and breast or prostate cancer on intravenous bisphosphonate therapy. J Oral Maxillofac Surg 65: 1328-1331.

2. Ruggiero SL, Mehrotra B, Rosenberg TJ, Engroff SL (2004) Osteonecrosis of the jaws associated with the use of bisphosphonates: a review of 63 cases. J Oral Maxillofac Surg 62: 527-534.

3. Marx RE (2003) Pamidronate (Aredia) and zoledronate (Zometa) induced avascular necrosis of the jaws: a growing epidemic. J Oral Maxillofac Surg 61: $1115-1117$.

4. Hoff AO, Toth B, Hu M, Hortobagyi GN, Gagel RF (2011) Epidemiology and risk factors for osteonecrosis of the jaw in cancer patients. Ann N Y Acad Sci 1218: $47-54$

5. (1993) Consensus Development Conference: Diagnosis, prophylaxis and treatment of osteoporosis. Am J Med 94: 646-650.

6. Dao TT, Anderson JD, Zarb GA (1993) Is osteoporosis a risk factor for osseointegration of dental implants? Int J Oral Maxillofac Implants 8: 137-144.
7. van Steenberghe D, Jacobs R, Desnyder M, Maffei G, Quirynen M (2002) The relative impact of local and endogenous patient-related factors on implant failure up to the abutment stage. Clin Oral Implants Res 13: 617-622.

8. Friberg B, Ekestubbe A, Mellstrom D, Sennerby L (2001) Brånemark implants and osteoporosis: a clinical exploratory study. Clin Implant Dent Relat Res 3: 50-56.

9. Holahan CM, Koka S, Kennel KA, Weaver AL, Assad DA, et al. (2008) Effect of osteoporotic status on the survival of titanium dental implants. Int $\mathrm{J}$ Oral Maxillofaci Implants 23: 905-910.

10. Lo JC, O'Ryan F, Yang J, Hararah MK, Gonzalez JR, et al (2011) Oral health considerations in older women receiving oral bisphosphonate therapy. J Am Geriatr Soc 59: 916-922.

11. Marx RE, Cillo JE Jr, Ulloa JJ (2007) Oral bisphosphonate-induced osteonecrosis: Risk factors, prediction of risk using serum CTX testing, prevention and treatment. J Oral Maxillofaci Surg 65: 2397-2410.

12. Bilezekian JP (2009) Efficacy of bisphosphonates in reducing fracture risk in post-menopausal osteoporosis. Am J Med 122: 14-21. 